BMC

Neuroscience

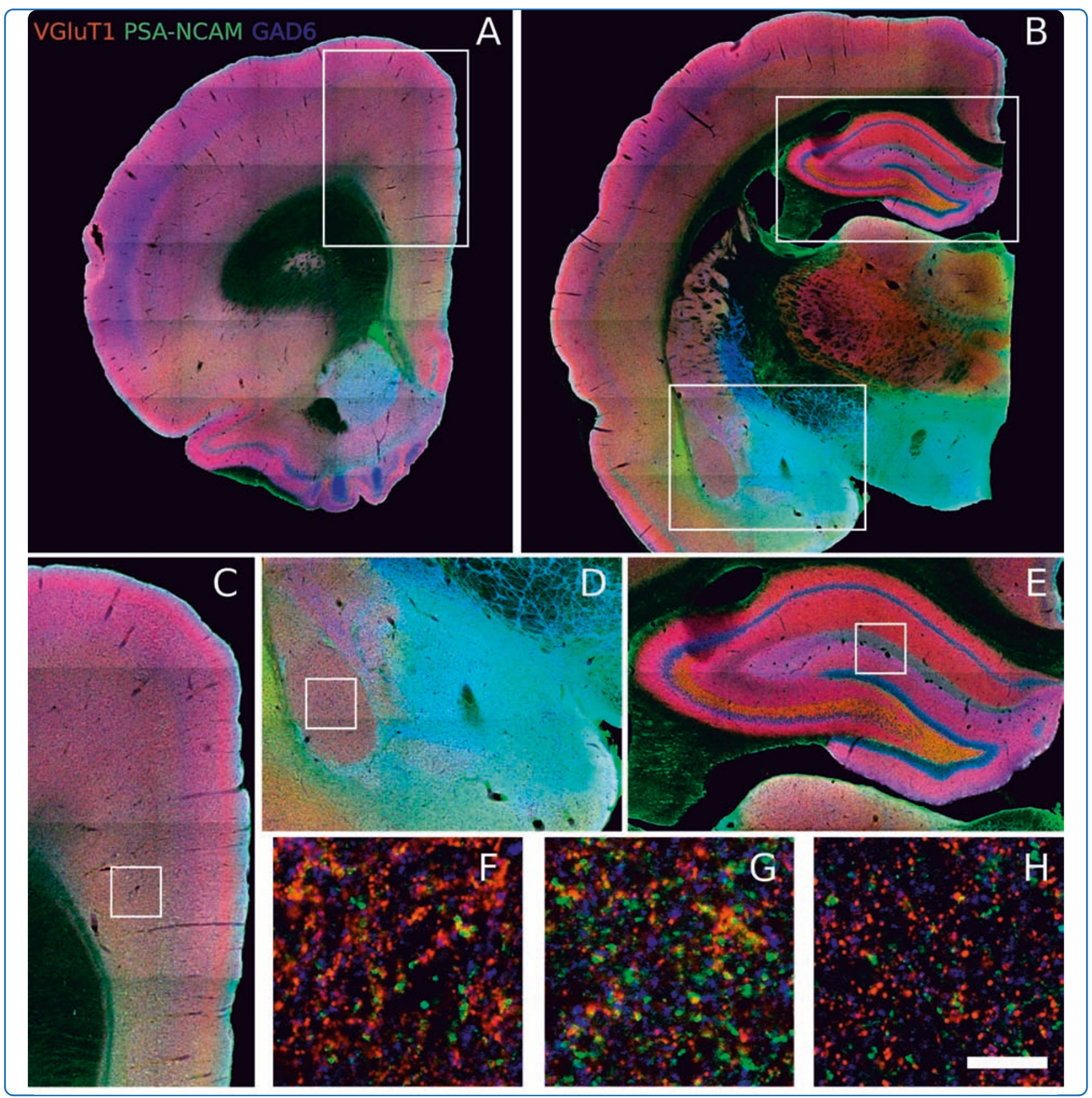

Chronic fluoxetine treatment in middle-aged rats induces changes in the expression of plasticityrelated molecules and in neurogenesis

Guirado et al.

() Biomed Central 


\title{
Chronic fluoxetine treatment in middle-aged rats induces changes in the expression of plasticity- related molecules and in neurogenesis
}

Ramon Guirado 1,2, David Sanchez-Matarredona', Emilo Varea ${ }^{1,2}$, Carlos Crespo ${ }^{1,2}$, José Miguel Blasco-Ibáñez ${ }^{1,2}$ and Juan Nacher ${ }^{1,2^{*}}$

\begin{abstract}
Background: Antidepressants promote neuronal structural plasticity in young-adult rodents, but little is known of their effects on older animals. The polysialylated form of the neural cell adhesion molecule (PSA-NCAM) may mediate these structural changes through its anti-adhesive properties. PSA-NCAM is expressed in immature neurons and in a subpopulation of mature interneurons and its expression is modulated by antidepressants in the telencephalon of young-adult rodents.

Results: We have analyzed the effects of 14 days of fluoxetine treatment on the density of puncta expressing PSANCAM and different presynaptic markers in the medial prefrontal cortex, hippocampus and amygdala of middleaged (8 months old) rats. The density of puncta expressing PSA-NCAM increased in the dorsal cingulate cortex, as well as in different hippocampal and amygdaloid regions. In these later regions there were also increases in the density of puncta expressing glutamic acid decarboxylase 65/67 (GAD6), synaptophysin (SYN), PSA-NCAM/SYN and PSA-NCAM/GAD6, but a decrease of those expressing vesicular glutamate transporter 1 (VGluT1). Since there is controversy on the effects of antidepressants on neurogenesis during aging, we analyzed the number of proliferating cells expressing Ki67 and that of immature neurons expressing doublecortin or PSA-NCAM. No significant changes were found in the subgranular zone, but the number of proliferating cells decreased in the subventricular zone.
\end{abstract}

Conclusions: These results indicate that the effects of fluoxetine in middle-aged rats are different to those previously described in young-adult animals, being more restricted in the MPFC and even following an opposite direction in the amygdala or the subventricular zone.

\section{Background}

Recent hypotheses support the idea that abnormalities in neuronal structural plasticity may underlie the etiopathogenesis of major depression [1,2]. Accordingly, it has been shown that patients and animal models of this disorder show changes in the volume of certain cerebral regions, such as the hippocampus, the medial prefrontal cortex or the amygdala, which are related to the reorganization of neuronal structure and may affect their connectivity $[3,4]$. However, these structural changes are not limited to neuronal remodeling, they may also affect

\footnotetext{
* Correspondence: nacher@uv.es

${ }^{1}$ Neurobiology Unit and Program in Basic and Applied Neurosciences, Cell Biology Dpt., Universitat de València, Spain

Full list of author information is available at the end of the article
}

the production of new neurons, specially in the adult hippocampus [5-8]. Interestingly, antidepressant treatment is able to revert or block this plasticity in experimental animals and humans [9-13]. In fact, different lines of evidence indicate that both neuronal remodeling [14-17] and adult neurogenesis [12,18] may play an important role in the way of action of antidepressant drugs.

The regulation of the expression of cell adhesion molecules is critical for the neuronal structural remodeling induced by aversive experiences or by antidepressant treatments [19]. Previous results from our laboratory have shown that chronic treatment with the serotonin $(5 \mathrm{HT})$ reuptake inhibitor fluoxetine, a commonly used antidepressant, influences the expression of the

\section{C) Biomed Central}


polysialylated form of the neural cell adhesion molecule (PSA-NCAM) in different regions of the CNS of youngadult animals [20,21]. Similar results have been obtained with another antidepressant, imipramine [17]. PSANCAM, due to its anti-adhesive properties, creates a steric impediment for cell adhesion and, consequently, promotes structural plasticity [22]. In fact, the changes in PSA-NCAM expression induced by chronic fluoxetine treatment are accompanied by parallel changes in the expression of the synaptic protein synaptophysin (SYN), suggesting the occurrence of synaptic remodeling [21]. PSA-NCAM expression is abundant during development and, although it decreases markedly during adulthood, it is still detectable in many cerebral regions, such as the medial prefrontal cortex (mPFC) [23,24], amygdala [25] and hippocampus [26], which are known to be involved in major depression. In these regions, PSA-NCAM is expressed in immature neu-rons, such as those in the hippocampal subgranular zone (SGZ) [27] and the subventricular zone (SVZ) [28], but it is also expressed in a subpopulation of mature interneurons [29,24], which have reduced syn-aptic input and morphological features compared with other interneurons lacking PSA-NCAM [30]. Pre-vious work in our laboratory demonstrated that $5 \mathrm{HT}$, acting via $5 \mathrm{HT} 3$ receptors is able to regulate PSA-NCAM expression in the mPFC of adult rats [20].

The effects of antidepressants on neuronal plasticity are not restricted to structural remodeling of neurons and their connections, they may also influence the generation and incorporation of new neurons in the adult CNS. Chronic antidepressant treatments increase neurogenesis in the SGZ of the dentate gyrus and the SVZ of young-adult rodents [31,32], and this increase appears to be required at least for part of the behavioral improvement observed in the treated animals [18]. However, other studies are in disagreement with these findings and have found that antidepressants do not produce an increase in neurogenesis in the SGZ [33,34].

Despite all these interesting findings regarding the effects of antidepressants on neuronal plasticity, it has to be noted that most of the experiments have been performed using young-adult rodents, usually 2-3 months old. Consequently, there is controversy on whether antidepressants, and specifically $5 \mathrm{HT}$ reuptake inhibitors, exhibit the same efficacy within different age groups. This is particularly interesting because aging influences both neurogenesis [35] and PSA-NCAM expression [36]. Studies on the effects of antidepressant treatment using older animals are still scarce: Only a few works have studied neurogenesis in the SGZ [32,37], but not in the SVZ and, to our knowledge, none has studied other types of neuronal structural plasticity.

We have analyzed the effects of 14 days of chronic fluoxetine treatment on middle-aged ( 8 month old) rat brains, studying the expression of PSA-NCAM and that of different presynaptic proteins in regions known to be specially affected in patients and in animal models of major depression, as well as by antidepressant treatment, such as the mPFC, the amygdala, and the hippocampus [38-42]. We have studied the expression of SYN a general synaptic marker, glutamic acid decarboxylase 65/67 (GAD6), a marker for inhibitory synapses and the vesicular glutamate transporter 1 (VGluT1), a marker of excitatory synapses. To study the effects of fluoxetine on adult neurogenesis, we have analyzed the numbers of im-mature cells, using immunohistochemistry for doublecortin (DCX) and PSA-NCAM, and those of proliferating cells with $\mathrm{Ki} 67$ in the two neurogenic niches of the adult brain: the SGZ and the SVZ.

\section{Methods}

\section{Animal treatments}

Fourteen adult male Wistar rats (8 months old) were used in this experiment. All the rats were maintained in standard conditions of light (12 hour cycles) and temperature, with no limit in the access to food or water. All animal experimentation was conducted in accordance with the Directive 2010/63/EU of the European Parliament and of the Council of 22 September 2010 on the protection of animals used for scientific purposes and was approved by the Committee on Bioethics of the Universitat de València. Every effort was made to minimize the number of animals used and their suffering. Rats were chronically injected intraperitoneally either with the antidepressant fluoxetine ( $\mathrm{n}=7,10 \mathrm{mg} / \mathrm{kg}$ ), or with saline solution ( $\mathrm{n}=7$ ), during 14 days (once daily at $10.00 \mathrm{am}$ ). Previous studies have shown that this dose produces behavioral changes and increases in the expression of plasticity-related molecules [21,58]. The day after these treatments, rats were perfused transcardially under deep chloral hydrate anesthesia (chloral hydrate $4 \%, 1 \mathrm{ml} / 100 \mathrm{gr}$ ), first with saline and then with $4 \%$ paraformaldehyde in so-dium phosphate buffer (PB $0.1 \mathrm{M}, \mathrm{pH} 7.4)$. After perfusion, the brains were extracted and cryoprotected with $30 \%$ sucrose in PB. Brains were cut into $50 \mu \mathrm{m}$ thick sections with a freezing sliding microtome, collected in 10 subseries and stored at $-20^{\circ} \mathrm{C}$ in $30 \%$ glycerol, $30 \%$ ethylene glycol in PB $0.1 \mathrm{M}$ until used.

\section{Immunohistochemistry}

Tissue was processed free-floating as follows: Briefly, sections were incubated for $1 \mathrm{~min}$ in an antigen unmasking solution (0.01 M citrate buffer, $\mathrm{pH}$ 6) at $100^{\circ}$ C. After cooling down the sections to room temperature, the endogenous peroxidase was blocked with 10 min incubation in a solution of $3 \% \mathrm{H}_{2} \mathrm{O}_{2}$ in phosphate buffered saline (PBS). Afterwards, slices were incubated 
in 10\% normal donkey serum (NDS) (Abcys SA), 0.2\% Triton-X100 (Sigma) in PBS with for 1 hour; then, they were incubated overnight at room temperature with goat polyclonal anti-doublecortin (DCX) (C-18; 1:250; Santa Cruz Biotechnology, Inc.), mouse monoclonal anti-PSA-NCAM IgM (1:1400; Abcys SA) or mouse monoclonal anti-Ki67 IgG (1:2000; Novocastra). After washing, sections were incubated for $30 \mathrm{~min}$ with biotinylated donkey anti-goat IgG, donkey anti-mouse IgM or donkey anti-mouse IgG (1:200; Jackson Immunoresearch) antibodies, followed by an avidin-biotin-peroxidase complex (ABC, Vector Laboratories) for $30 \mathrm{~min}$ in PBS. Color development was achieved by incubating with $0,5 \% 3,3$ ' diaminobenzidine tetrahydrochloride (DAB, Sigma) and $\mathrm{H} 2 \mathrm{O} 2$ for $4 \mathrm{~min}$. All the sections passed through all procedures simultaneously to minimize any difference from immunohistochemical staining itself.

For double fluorescence immunohistochemistry, slices were incubated overnight with rabbit polyclonal antisynaptophysin (SYN) IgG (1:1000; Chemicon Int. Inc.) and mouse monoclonal anti-PSA-NCAM IgM (1:1400; Abcys SA). Then, were incubated for 1 hour with donkey anti-rabbit IgG Dylight 488 and donkey anti-mouse IgM Dylight 555 (1:200; Jackson Immunoresearch).

For triple immunohistochemistry, the procedure was similar but using a combination of anti-PSA-NCAM, anti-glutamic acid decarboxylase 65/67 (GAD6; 1:500; Developmental Studies Hybridoma Bank) and anti-vesicular glutamate transporter (VGluT1; 1:2000; Chemicon Int. Inc.) antibodies. In this case the following secondary antibodies were used: anti-mouse IgM Dylight 555, antimouse IgG subtype 1 specific Dylight 488 and anti-guinea pig IgG Dylight 647 respectively.

\section{Quantitative analysis}

All the slides containing sections destined to quantitative analysis were coded and their code was not broken until the analyses were finished.

The volume of the mPFC, the hippocampus and the lateral and basolateral region of the amygdala was estimated using Volumest, an ImageJ plugin for volume estimation using an stereological method. For this analysis we used the tissue processed with PSA-NCAM immunohistochemistry and developed with $\mathrm{DAB}$ was used.

The images used for the analysis of neuropil puncta were obtained with a confocal microscope (Leica TCS SPE) and parallel subseries of Nissl stained sections were used as guides to help locate the regions of interest. We analyzed layer $\mathrm{V}$ of two different regions of the medial prefrontal cortex (mPFC): the prelimbic cortex $(\mathrm{PrL})$ in a single section corresponding to Bregma +2.20 $\mathrm{mm}$ and another one of the dorsal cingulate cortex
(Cg2) (Bregma $+1 \mathrm{~mm}$ ). In the amygdala, five nuclei were analyzed in one section (Bregma $-3.30 \mathrm{~mm}$ ): basomedial, lateral, medial, central and basolateral. Different regions and strata of the hippocampus were also analyzed in another section (Bregma $-4.30 \mathrm{~mm}$ ): the molecular layer of the dentate gyrus, the strata lacunosum-moleculare, radiatum and oriens of CA1 and the stratum lucidum of CA3. Confocal z-stacks covering the whole depth of the sections were taken with $1 \mu \mathrm{m}$ step size and only subsets of confocal planes with the optimal penetration level for each antibody were selected. On these planes, small regions of the neuropil (505 $\mu \mathrm{m}^{2}$ ) were selected for analysis, in order to avoid blood vessels and cell somata.

Images were processed using ImageJ software as follows: the background was substracted with rolling value of 50, converted to 8-bit deep images and binarized using a determined threshold value. This value depended on the marker and the area analyzed and was kept the same for all images with the same marker and area. Then, the images were processed with a blur filter to reduce noise and separate closely apposed puncta. Finally, the number of the resulting dots per region was counted, as well as the colocalization between PSANCAM and the different pre-synaptic markers (Additional File 1, Figure S1). In addition, we also analyzed the size of the dots and the total surface covered by the puncta after binarization. Means were determined for each animal group and the data were subjected to two-way ANOVAs with repeated measures followed by Bonferroni post hoc test.

The density of DCX, PSA-NCAM and Ki67 expressing cells in the SGZ of the dentate gyrus was estimated as described before [25]. Briefly, sections were selected by a 1:10 fractionator sampling covering the whole rostral to caudal extension of the dentate gyrus and on each section all labeled cells within the region of interest were counted. Cell somata were identified and counted with a $40 \times$ objective using an Olympus CX41 microscope. The volume of the different areas analyzed was determined for each animal using the Cavalieri's method. Student's t-test was performed for statistical analysis.

In the SVZ, a single section between Bregma +0.48 and $+0.7 \mathrm{~mm}$, was analyzed for DCX, PSA-NCAM and Ki67 immunohistochemistry. The number of immunoreactive cells was estimated following a modification of the method described by Hansson et al. [43]. Ki67 expressing nuclei were counted using automatic counting software as described above for immunoreactive puncta, analyzing an area of $100 \mu \mathrm{m}^{2}$ and then expressed as the number of immunoreactive positive cells per $\mathrm{mm}^{2}$. Densities of DCX and PSA-NCAM expressing cells were too high for a correct individual 
cell count. Therefore, we performed densitometry of small areas within the SVZ, using a $40 \times$ magnification, as described before [20].

\section{Results \\ Weight of the animals and volume of the different structures analyzed}

In concordance with previous studies [44,45], chronic fluoxetine treatment produced a significant diminution of weight gain $(\mathrm{p}<0.001)$ after 14 days, when comparing the relation final weight/initial weight between the treated animals $(0.877 \pm 0.017)$ and the controls $(1.017$ \pm 0.009) (Figure 1).

We also analyzed the effects of chronic fluoxetine treatment on the volume of the different cerebral structures studied. We did not observe changes in the volume of the mPFC or the amygdala, but we found an increase in the volume of the hippocampus of the animals treated with fluoxetine $(p=0.001$, Figure 1).

\section{Expression of plasticity-related Molecules Medial prefrontal cortex}

The expression pattern of PSA-NCAM in the MPFC was similar to that described previously [23]: All regions within the $\mathrm{mPFC}$ showed a moderate intensity of staining in layer I, nearly lack of staining in layer II, weak staining in layer III and intense staining in layers V-VI (Figure 2).

In this cortical region, there was an increase in the density of PSA-NCAM expressing puncta in the fluoxetine treated animals in the dorsal cingulate cortex $(\mathrm{Cg} 2)$ $(\mathrm{p}=0.043)$, but not in the prelimbic cortex (PrL) (Figure 3 and Additional File 2, Table S1). No differences were found in the density of puncta expressing synaptophysin (SYN), glutamic acid decarboxylase 65/67 (GAD6), or vesicular glutamate transporter 1 (VGluT1) in any of the regions studied (Figure 3 and Additional File 2, Table S1)). We did not find changes in the density of puncta colocalizing PSA-NCAM/SYN, PSA-

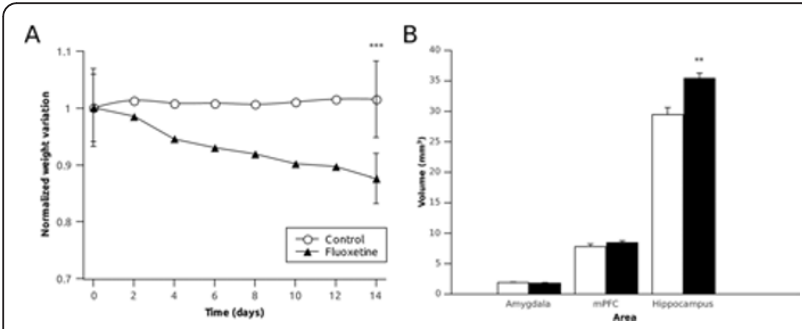

Figure 1 Graphs showing (A) the body weight change through the experiment for the control and fluoxetine group and (B) the effect of the chronic fluoxetine treatment on the volume of the different structures studied. Statistically significant ${ }^{*} \mathrm{P}<$ 0.05 , ** $P<0.01$, *** $P<0.001)$ Student t-test.
NCAM/GAD6 or PSA-NCAM/VGluT1 neither in the PrL nor in the Cg2 (Figure 2 and Additional File 2, Table S1).

We did not find changes neither in the dot size nor in the surface covered by puncta in any of the regions and the markers analyzed (Additional File 3, Figure S2).

\section{Amygdala}

As described previously [24], low levels of PSA-NCAM expression were found in the neuropil of the lateral and basolateral amygdaloid nuclei. By contrast, PSA-NCAM expression was denser and more intense in the central, medial and basomedial nuclei (Figure 2).

In the fluoxetine treated group we found significant increases in the density of PSA-NCAM expressing puncta in the central amygdaloid nucleus $(\mathrm{p}=0.001)$, of SYN expressing puncta in the lateral $(p=0.049)$ and basolateral amygdaloid nuclei $(p=0.047)$ and of GAD6 expressing puncta in the basolateral nucleus $(\mathrm{p}=0.005)$ (Figure 4 and Additional File 2, Table S1). On the contrary, we found a significant decrease in the number of VGluT1 expressing puncta in the basolateral amygdaloid nucleus ( $\mathrm{p}=0.04$ ) (Figure 4 and Additional File 2, Table $\mathrm{S} 1)$. We also found an increase in PSA-NCAM/SYN (p $=0.007)$ and PSA-NCAM/GAD6 $(\mathrm{p}=0.041)$ expressing puncta in the central amygdala. No changes in the density of these double-labeled puncta were observed in any of the other amygdaloid nuclei studied (Figure 4 and Additional File 2, Table S1).

We also found changes similar to those described for puncta density when analyzing the dot size and the surface covered by these puncta. In the central amygdaloid nucleus we observed an increase both in the dot size and the surface covered by PSA-NCAM expressing puncta $(p=0.027$ and 0.011$)$. In the lateral nucleus we only observed an increase in the dot size of puncta expressing SYN ( $\mathrm{p}=0.038$ ). By contrast, in the basolateral nucleus we found an increase in the dot size and surface covered by puncta expressing GAD6 ( $\mathrm{p}=0.011$ and 0.018) and a decrease in both, the dot size and the surface covered by puncta expressing VGluT1 ( $\mathrm{p}=$ 0.005 and 0.007) (Additional File 4, Figure S3).

\section{Hippocampus}

PSA-NCAM expression in the hippocampus was similar to that described previously [26]: briefly, the most intense expression of PSA-NCAM was located in the somata and apical dendrites of granule cells in the SGZ of the dentate gyrus, as well as in the neuropil of the hilus and the mossy fibers. A weaker and more diffuse expression of PSA-NCAM could be found in the neuropil of other regions of the hippocampus, such as the molecular layer of the dentate gyrus and the strata lacunosum-moleculare, radiatum and oriens of CA1 and CA3 (Figure 2), where PSA-NCAM expressing cell somata could also be found [29]. 


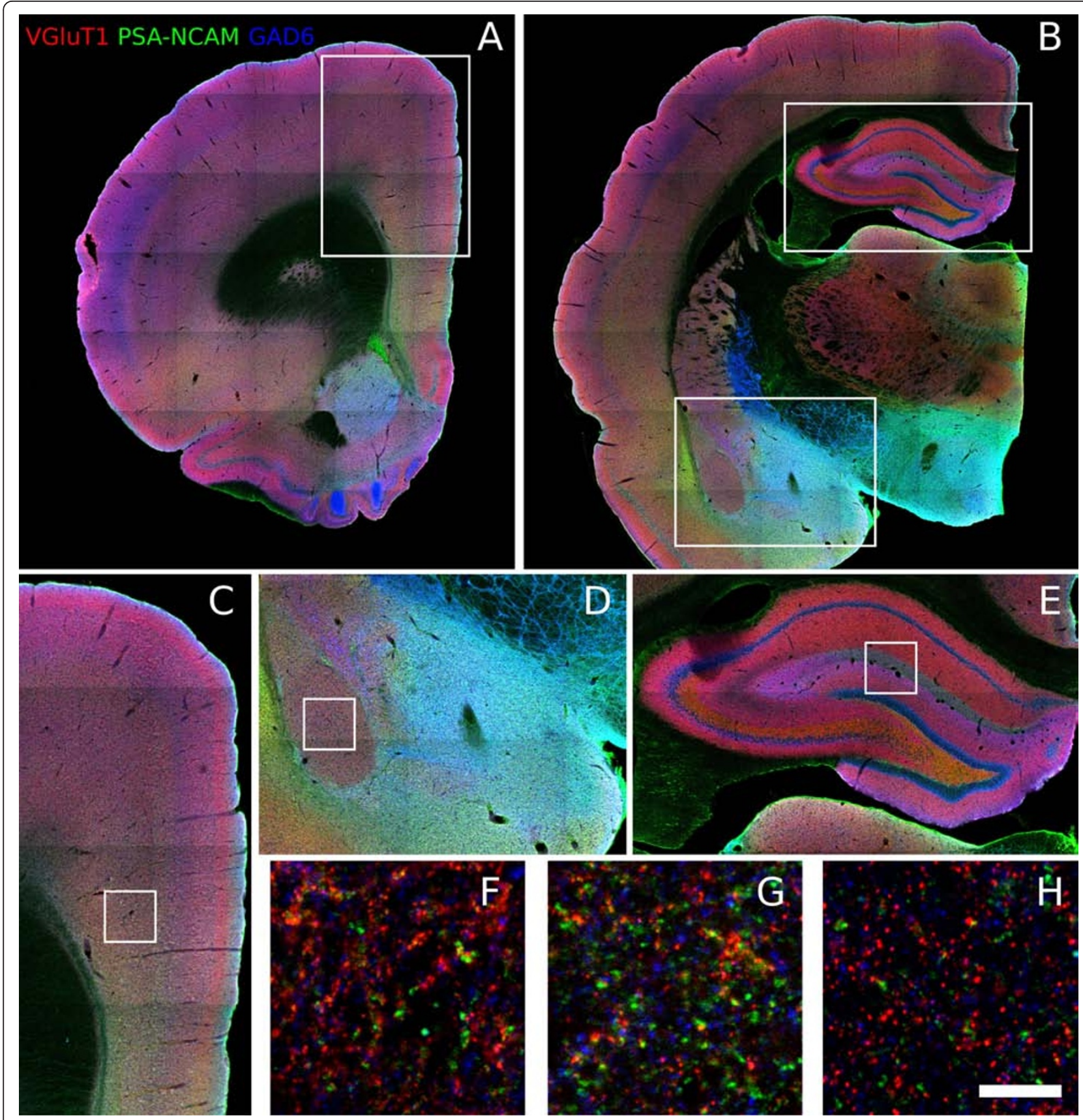

Figure 2 Confocal images showing the expression of PSA-NCAM, VGluT1 and GAD6 in the different regions of the hippocampus (B, E and $\mathbf{H})$, the amygdala (B, D and G) and the $\operatorname{mPFC}(\mathbf{A}, \mathbf{C}$ and $\mathbf{F})$. Scale bar $=200 \mu \mathrm{m}$ in $A$ and $B, 100 \mu \mathrm{m}$ in $C, D$ and $E$ and $1 \mu \mathrm{m}$ in $F, G$ and $\mathrm{H}$.

After chronic fluoxetine treatment, we found significant increases in the density of PSA-NCAM expressing puncta in the molecular layer $(\mathrm{p}=0.045)$, stratum lucidum $(\mathrm{p}=0.032)$ and stratum lacunosum-moleculare $(\mathrm{p}$ $<0.001$ ) (Figure 5 and Additional File 2, Table S1). Similar increases were found in the density of SYN expressing puncta in the strata lucidum $(\mathrm{p}=0.012)$ and lacunosum-moleculare $(\mathrm{p}=0.038)$. We also found a significant increase $(\mathrm{p}=0.018)$ in the density of GAD6 expressing puncta in the stratum lacunosum-moleculare. By contrast, we found a decrease in the density of VGluT1 expressing puncta in the strata lacunosummoleculare $(\mathrm{p}=0.021)$ and radiatum $(\mathrm{p}=0.030)$ of CA1 (Figure 5 and Additional File 2, Table S1). When studying the density of puncta co-expressing PSA-NCAM and each of the other markers, we observed an increase 


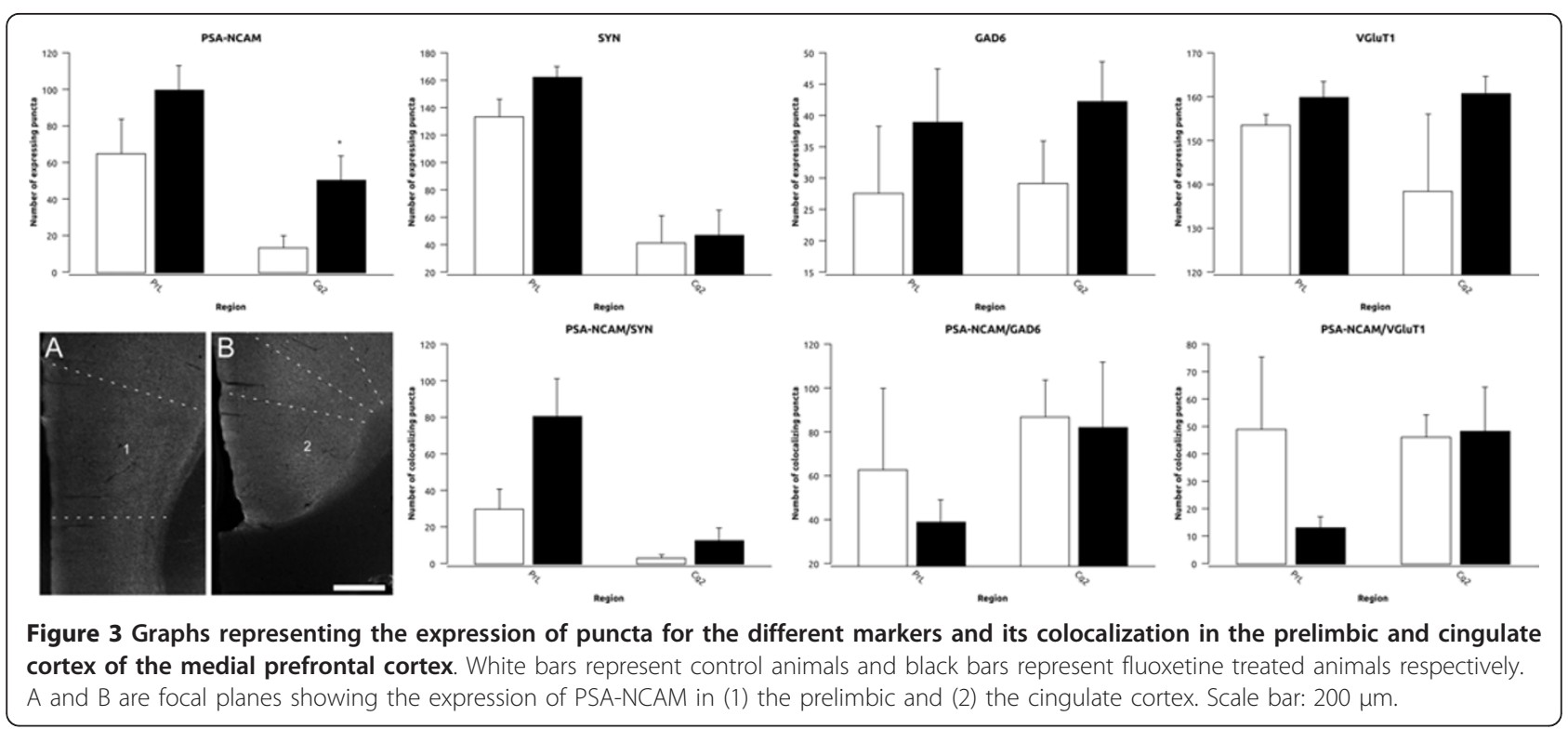

in the density of puncta co-expressing PSA-NCAM/SYN $(\mathrm{p}=0.008)$ in the stratum lacunosum-moleculare, but no change was observed in those co-expressing PSANCAM/GAD or PSA-NCAM/VGluT1 (Figure 5 and Additional File 2, Table S1).

Finally, when analyzing the dot size and the surface covered by immunoreactive puncta, we also observed changes in most of the regions that showed differences in the density of puncta in these structures. In the stratum lacunosum-moleculare we observed an increase in the dot size and the surface covered by puncta expressing PSA-NCAM ( $\mathrm{p}=0.011$ and $<0.001)$ and GAD6 ( $\mathrm{p}$ $=0.047$ and 0.021 ), while there was only an increase in dot size in those expressing SYN $(\mathrm{p}=0.044)$ and a decrease in both dot size and surface covered by those expressing VGluT1 ( $\mathrm{p}=0.035$ and 0.017$)$. We also find a decrease in both the dot size and the surface covered by puncta expressing VGluT1 in the stratum radiatum $(\mathrm{p}=0.015$ and 0.007$)$ (Additional File 5, Figure S4).

\section{Adult neurogenesis}

No change in the density of cells expressing DCX or PSA-NCAM was observed in the subgranular zone (SGZ) of the dentate gyrus after chronic fluoxetine treatment (Figure 6). However, when analyzing the number of Ki67 expressing nuclei there was a trend

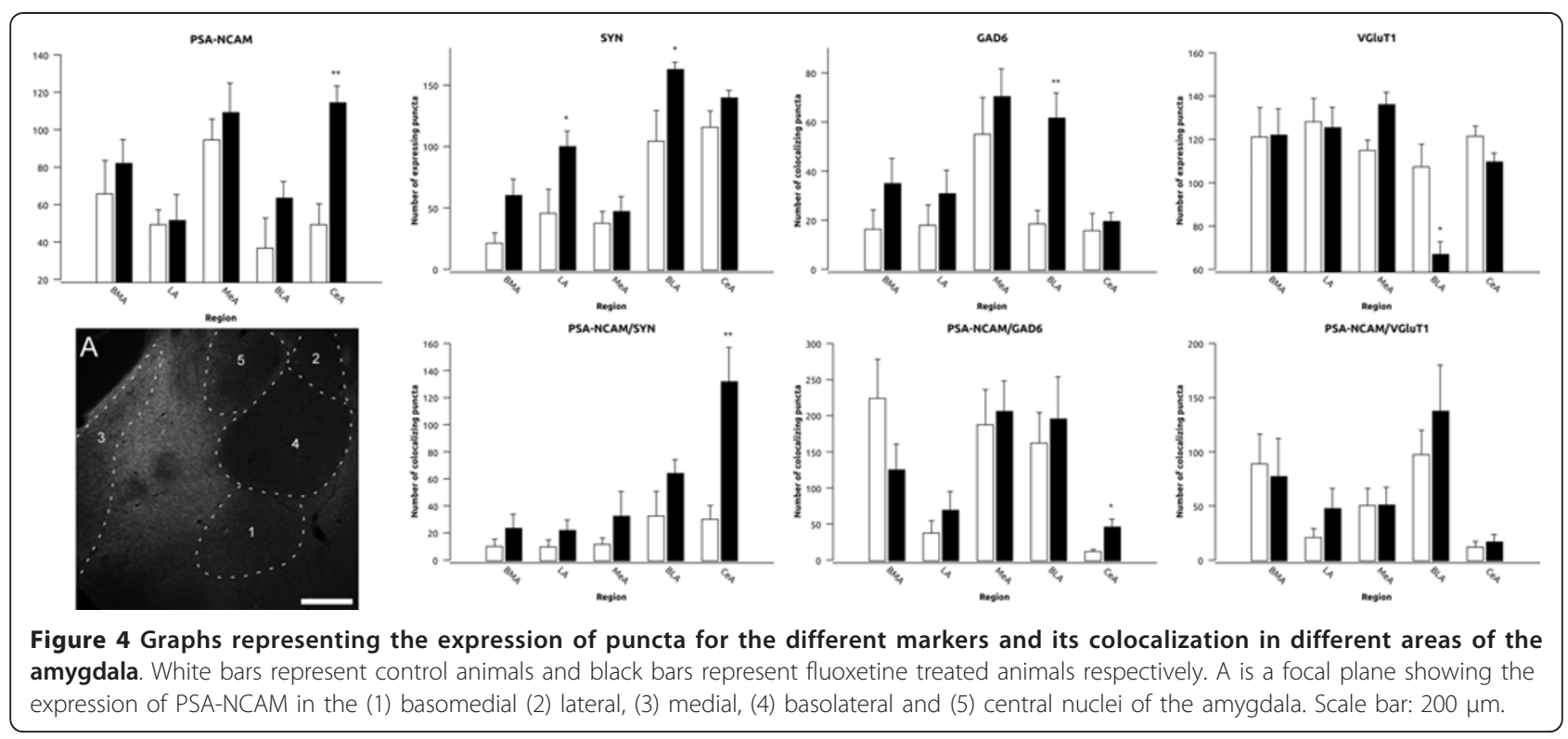



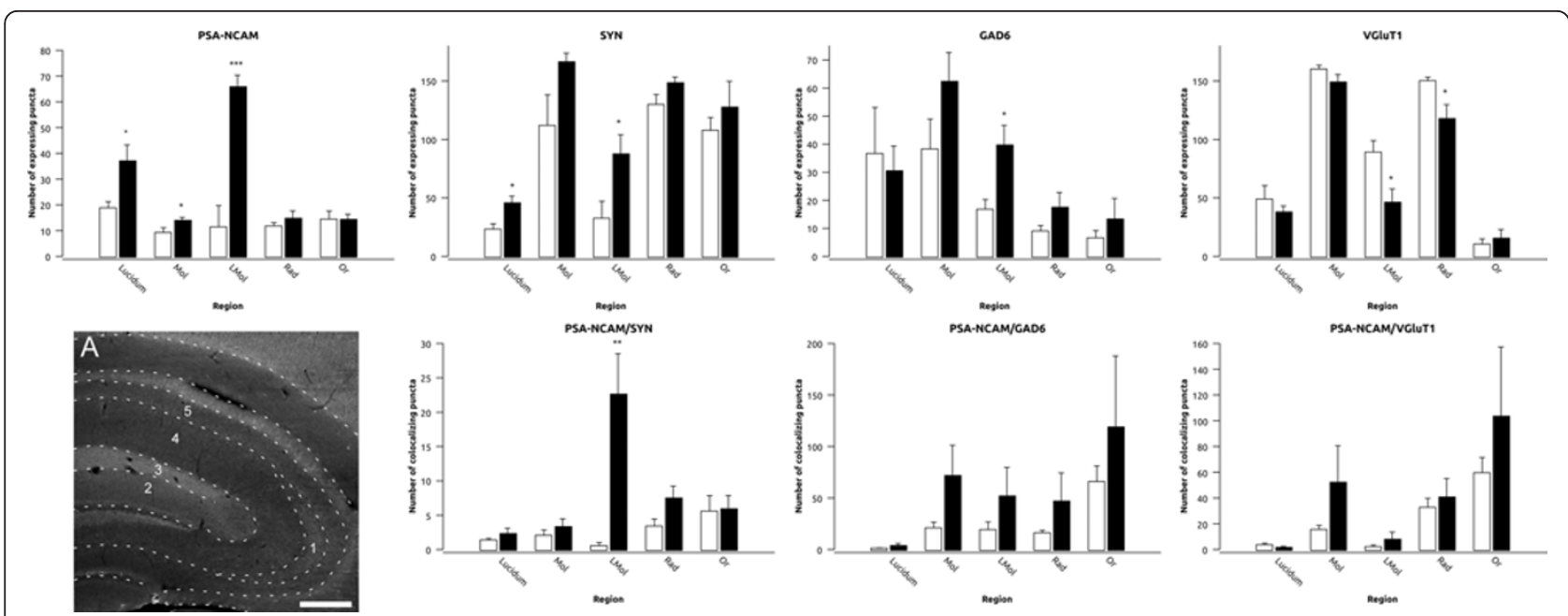

Figure 5 Graphs representing the expression of puncta for the different markers and its colocalization in different areas of the hippocampus. White bars represent control animals and black bars represent fluoxetine treated animals respectively. A is a focal plane showing the expression of PSA-NCAM in the strata (1) Lucidum, (2) Molecular, (3) Lacunosum Moleculare, (4) Radiatum and (5) Oriens of the hippocampus. Scale bar: $200 \mu \mathrm{m}$.

towards a decrease in the treated group $(\mathrm{p}=0.061)($ Figure 6). In the subventricular zone (SVZ) we also failed to find changes in the expression of DCX or PSANCAM, but we observed a dramatic significant decrease in the number of Ki67 immunoreactive nuclei in the treated group $(\mathrm{p}<0.001)$ (Figure 6).

\section{Discussion}

Our results indicate that in middle-aged rats chronic fluoxetine treatment induces changes in the expression of molecules related to neuronal structural plasticity. These changes occur in the same direction of those observed previously in young-adult animals in the hippocampus and the mPFC, although to a reduced extent in this later region. However, they follow the opposite direction in the amygdala. We have also observed that, in contrast with what has been observed in young-adult rats, there is a negative impact of fluoxetine on cell proliferation in the SVZ and apparently a lack of effect in the SGZ.

\section{PSA-NCAM expression as an indicator of neuronal structural plasticity}

Previous experiments have demonstrated that PSANCAM expression is sensible to fluoxetine treatment, acting through 5HT3 receptors [20]. However, since other $5 \mathrm{HT}$ receptors are known to mediate the effects of fluoxetine, they may also influence PSA-NCAM expression [46-51]. Many PSA-NCAM expressing structures in the cerebral cortex $[24,29,30]$ and the amygdala [52] of rodents belong to mature interneurons. Consequently, changes in PSA-NCAM expression should primarily affect the structure of these inhibitory. In this line, we have recently reported that PSA-NCAM expressing cortical interneurons have reduced synaptic input and decreased dendritic arborization and spine density when compared with neighboring interneurons lacking PSA-NCAM [30]. In fact, a previous report from our laboratory using a dopamine D2 receptor antagonist, which increases PSA-NCAM expression in the mPFC, also resulted in a parallel upregulation of GAD67 expression [53]. It is possible then, that the changes in PSA-NCAM expression observed in the present study affect the connectivity of certain interneurons, regulating the surface of preexisting plasma membrane available for the establishment of synaptic contacts. Another nonexcluding possibility may be that, given its anti-adhesive properties, changes in PSA-NCAM expression may regulate the ability of certain interneurons to remodel the structure of their neurites, and consequently their connections, in response to fluoxetine treatment.

Comparison of the effects of chronic fluoxetine treatment on the expression of PSA-NCAM and presynaptic markers between middle-aged and young-adult animals

The present results in the $\mathrm{mPFC}$, showing only an increase in the density of PSA-NCAM expressing puncta in the dorsal cingulate cortex, are more restricted than those found previously in young-adult rats, which showed increases in every region and layer of the mPFC [20]. The lack of changes in the density of puncta expressing presynaptic markers is also in contrast with previous reports using young-adult rats, which showed increases in SYN expression in deep layers of the prelimbic and infralimbic cortices [21] and of VGluT-1 mRNA expression in the cingulate cortex [54]. 


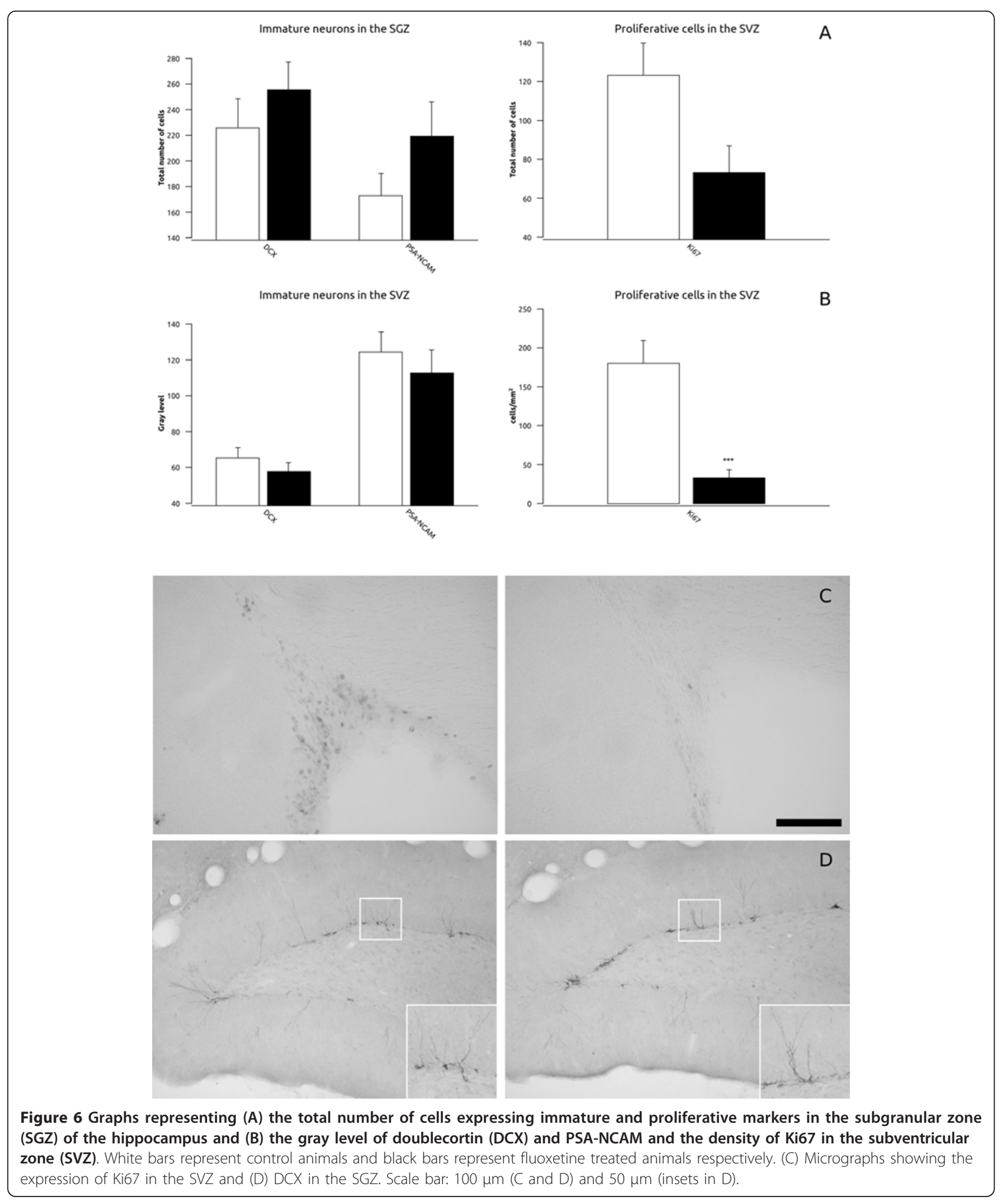

In the hippocampus, previous studies with youngadult rats found a similar increase in PSA-NCAM expression in the stratum lucidum, but not in the rest of hippocampal strata studied [21]. Since in young-adult rats antidepressants promote an increase in the density of PSA-NCAM expressing cells in the SGZ [17], fluoxetine may be affecting PSA-NCAM expression in the stratum lucidum by increasing the production or 
accelerating the maturation of immature granule cells, some of which may have already sent PSA-NCAM expressing mossy fibers to this layer [55]. However, our results clearly indicate that the number of these cells is not affected by fluoxetine in middle-aged rats, suggesting that changes in PSA-NCAM expressing puncta are not linked to adult neurogenesis. In connection to this, a recent report has shown that chronic fluoxetine treatment may produce a dematuration of granule cells [56]. Since many mossy fibers in the stratum lucidum are polysialylated by St8SiaII, the enzyme responsible for the polysialylation of immature neurons in the adult cerebral cortex [57], this putative dematuration induced by fluoxetine may explain the increase in PSA-NCAM expression that we observe in this stratum. In consonance with this hypothesis and with previous studies in young-adult rats $[21,58]$, we have failed to find any significant difference in the density of SYN expressing puncta in the stratum lucidum, which may indicate that the changes in PSA-NCAM are not related to the genesis of new functional synaptic contacts. By contrast, the increase of PSA-NCAM expressing puncta in the stratum lacunosum-moleculare of middle-aged rats is accompanied by an increase in the density of SYN expressing puncta and of puncta co-expressing PSANCAM/SYN, suggesting that these structures correspond to synapses. Interestingly, in the stratum lacunosum-moleculare of middle-aged animals we also found an increase in the density of GAD6 expressing puncta, and a decrease in the density of those expressing VGluT1, which may indicate that the upregulation of PSA-NCAM expression may be linked to changes in inhibitory circuits, probably involving the formation of inhibitory synapses.

Chronic fluoxetine treatment in young-adult rats decreases PSA-NCAM and SYN expression in most amygdaloid nuclei [21] and decreases the number of PSA-NCAM expressing neurons in this limbic region [59]. By contrast, in middle-aged rats we not only have failed to observe decreases in the density of puncta expressing PSA-NCAM or SYN, but have observed significant increases in the density of PSA-NCAM expressing puncta in the central nucleus and of those expressing SYN in the lateral and basolateral nuclei. There is, in fact, a general tendency for an increase in the density of puncta expressing PSA-NCAM, SYN and GAD6 in all the amygdaloid nuclei studied. Moreover, despite the fact that no significant changes in puncta expressing exclusively GAD6 or SYN were observed in the central amygdala, the density of puncta coexpressing PSA-NCAM and each of these two markers also increases significantly, suggesting that changes in PSANCAM expression may be associated to the generation or remodeling of inhibitory synapses in this region. In the basolateral amygdala, chronic fluoxetine treatment may also influence positively synaptic plasticity of inhibitory circuits, as indicated by increased densities of GAD6 and SYN expressing puncta, while the density of those expressing VGluT1 is decreased.

It is possible that substantial differences in $5 \mathrm{HT}$ content and in the expression of its receptors, transporters, etc... exist in middle-aged animals. The levels of 5HT are generally reduced in the brain of aged rats [60] and, although there are no studies in middle-aged animals, it is possible that they are already reduced at this age. There is also evidence indicating that the expression 5 HT1A receptor, which has an important role in the antidepressant effects of $5 \mathrm{HT}$ reuptake inhibitors $[61,62]$, is lower in young-adult than in adolescent rats [59]. Additionally, other factors such as changes in inhibitory neurotransmission may also influence the effects of fluoxetine in middle-aged animals, particularly in the amygdala, where decreases in GABA concentration and hyperactivity have been described during aging [63,64].

\section{Effects of fluoxetine treatment on neurogenesis}

The present results on adult hippocampal neurogenesis are in agreement with previous studies showing that neither proliferation nor neuronal survival/differentiation is affected by chronic antidepressant treatment in middle-aged rodents [32,37]. This lack of response of the SGZ in middle-aged animals must be due to changes that alter the molecular pathways by which $5 \mathrm{HT}$ stimulates neurogenesis. There is an age-dependent reduction in the levels of 5HT [60] and some of its receptors [65] in the hippocampus. Since glucocorticoids are important modulators of adult hippocampal neurogenesis and these steroids are particularly elevated during aging [66], they may also influence the neurogenic response to antidepressants in middle-aged animals. In fact, glucocorticoids decrease 5HT transporter expression [67] and the neurogenic action of fluoxetine is blocked by a flattened corticosterone rhythm induced by artificially enhanced glucocorticoid levels [68]. Additionally, a previous study has clearly shown that intraperitoneal injections per se have effects on the structure of neurons, at least in the mPFC [69]. This effects are similar to those observed after chronic stress [41] and it is very likely that this procedure also affects some of the plasticity parameters measured in our study, including neurogenesis, which is importantly influenced by chronic stress [8].

Other molecules known to modulate adult neurogenesis, including neurotransmitters, such as glutamate acting on NMDA receptors [70] and GABA [71], or trophic factors, such as BDNF [72], can be influenced by antidepressants, including fluoxetine [73-76]. Consequently, age-dependent changes in their expression or in the molecular pathways in which these molecules are 
involved may also lead to changes in the pro-neurogenic effects of antidepressants.

In contrast with previous studies using fluoxetine [31] and 5HT receptor agonists [77] in young-adult rodents, which found increases in the number of proliferating cells in the SVZ, we have found the opposite effect. On the other hand, our results are in agreement with a recent report describing that in young-adult mice 3 weeks of fluoxetine treatment do not affect cell proliferation in the SVZ, but that the extension of this treatment to 6 weeks produces a significant deficit in the number of dividing cells in this region [78]. These results indicate that the SVZ of middle-aged rodents is more sensible to fluoxetine treatment, since a significant decrease in cell proliferation can be achieved with a shorter treatment. It is possible that the lack of differences in the number of neuroblasts in the SVZ may be due to a homeostatic parallel change in the number of apoptotic cells in this region, as suggested previously [79]. Alternatively, fluoxetine could impair neuronal migration, which may cause accumulation of neuroblasts in the SVZ.

\section{Implication of the present results on antidepressant therapy}

In light of the neuroplastic hypothesis of depression [1], our results indicate that antidepressant treatment in middle-aged individuals also has an important impact on neuronal structure and connectivity. Consequently, it may have relevant consequences on the therapeutics of major depression. In the present results, we have shown that chronic fluoxetine treatment increases the volume of the hippocampus and the expression of molecules related to structural plasticity and inhibitory neurotransmission. These phenomena may counteract the decreases in hippocampal volume and balance the increases in excitatory neurotransmission observed in depressed patients and in animal models of this disorder [8]. Similar, although lighter, effects have been observed in the amygdala. In this region, the increases in the expression of molecules related to structural plasticity and inhibitory neurotransmission may compensate the structural changes observed in inhibitory and excitatory neurons, which accompany the increased excitation observed in this limbic region in animal models of depression [80]. The effects of fluoxetine in the mPFC of middle-aged rats are more discrete, but it is reasonable to think that the increase in PSA-NCAM expression may facilitate compensatory structural changes to overcome the structural atrophy of pyramidal neurons observed in animal models of depression [42].

By contrast, our results on the effects of fluoxetine on adult neurogenesis do not seem to give support to the idea that this type of plasticity is important for the treatment of depression, at least in middle-aged rodents. It has to be noted, however, that our experiment has been performed in control animals and that the effects of fluoxetine on molecules related to neuronal structural plasticity or in neurogenesis may be more intense or follow a different direction when applied to animal models of this psychiatric disorder.

\section{Conclusions}

Our results indicating substantial differences in the plastic response of the CNS to fluoxetine in middle-aged animals may be relevant when considering what are the cellular bases of the behavioral changes associated to antidepressant action.

As it happens with rodents, middle-aged humans may also show reduced plasticity in response to antidepressant and, what is more important, this plasticity may follow a different direction in certain brain regions, such as the SVZ or the amygdala. These results indicate that the response to antidepressant treatment is more complex than previously thought and that the age of the subjects receiving these drugs is an important factor to consider and a subject for more intensive research.

\section{Additional material}

Additional file 1: Quantification of PSA-NCAM and SYN expressing
puncta in the hippocampus. Confocal image showing the expression
of PSA-NCAM and SYN in the hippocampus. Focal planes showing the
original image and the processed image for the puncta analysis for (B1
and B2) PSA-NCAM, (C1 and C2) SYN and (D1 and D2) the composite
image. Scale bar: $320 \mu \mathrm{m}$ in A and $5 \mu \mathrm{m}$ in the rest.

Additional file 2: Statistical values of puncta expressing different markers. Statistical information of the expression of the different markers and its colocalization in the diferent regions of the $\mathrm{MPFC}$, the hippocampus and the amygdala.

Additional file 3: Graphs for the dot size and surface covered by puncta expressing different markers in the Mpfc. Graphs representing the dot size and surface covered by puncta expressing different markers in the prelimbic and cingulate cortex of the medial prefrontal cortex. White bars represent control animals and black bars represent fluoxetine treated animals respectively.

Additional file 4: Graphs for the dot size and surface covered by puncta expressing different markers in the amygdala. Graphs representing the dot size and surface covered by puncta expressing different markers in different areas of the amygdala. White bars represent control animals and black bars represent fluoxetine treated animals respectively.

Additional file 5: Graphs for the dot size and surface covered by puncta expressing different markers in the hippocampus. Graphs representing the dot size and surface covered by puncta expressing different markers in different areas of the hippocampus. White bars represent control animals and black bars represent fluoxetine treated animals respectively.

\section{Acknowledgements and funding}

Spanish Ministry of Science and Innovation (MICINN-FEDER) BFU2009-12284/ BFI, MICINN-PIM2010ERN-00577/NEUCONNECT in the frame of ERA-NET NEURON" and the Stanley Medical Research Institute to JN. Ramón Guirado 
has a FPI predoctoral fellowship from the Spanish Ministry of Education and Science (BES 2007-15757).

\section{Author details}

${ }^{1}$ Neurobiology Unit and Program in Basic and Applied Neurosciences, Cell Biology Dpt., Universitat de València, Spain. ${ }^{2}$ INCLIVA: Fundación Hospital Clínico Universitario de Valencia, València, Spain.

\section{Authors' contributions}

RG carried out the animal experimentation, the histology, the image acquisition and processing, the statistics and drafted the manuscript. DSM participated in the image acquisition and processing. EV, CC and JMBI have revised critically the content of the manuscript. JN conceived and designed the experimental work, helped to draft the manuscript and wrote its final version. All authors read and approved the final manuscript.

\section{Competing interests}

The authors declare that they have no competing interests.

Received: 26 September 2011 Accepted: 5 January 2012

Published: 5 January 2012

\section{References}

1. Castrén E: Is mood chemistry? Nature Reviews Neuroscience 2005, 6:241-6.

2. Mattson MP, Maudsley S, Martin B: BDNF and 5-HT: a dynamic duo in age-related neuronal plasticity and neurodegenerative disorders. Trends in Neurosciences 2004, 27:589-94.

3. Phillips ML, Drevets WC, Rauch SL, Lane R: Neurobiology of emotion perception II: Implications for major psychiatric disorders. Biological Psychiatry 2003, 54:515-28.

4. Tata DA, Anderson BJ: The effects of chronic glucocorticoid exposure on dendritic length, synapse numbers and glial volume in animal models: implications for hippocampal volume reductions in depression. Physiology \& Behavior 2010, 99:186-93.

5. Duman RS, Malberg J, Nakagawa S, D'Sa C: Neuronal plasticity and survival in mood disorders. Biological Psychiatry 2000, 48:732-9.

6. Jacobs BL, van Praag H, Gage FH: Adult brain neurogenesis and psychiatry: a novel theory of depression. Molecular Psychiatry 2000, 5:262-9.

7. Kempermann G, Kronenberg G: Depressed new neurons-adult hippocampal neurogenesis and a cellular plasticity hypothesis of major depression. Biological Psychiatry 2003, 54:499-503.

8. McEwen BS: Effects of adverse experiences for brain structure and function. Biological Psychiatry 2000, 48:721-31.

9. Boldrini M, Underwood MD, Hen R, Rosoklija GB, Dwork AJ, John Mann J, Arango $\mathrm{V}$ : Antidepressants increase neural progenitor cells in the human hippocampus. Neuropsycho-pharmacology 2009, 34:2376-89.

10. Henn FA, Vollmayr B: Neurogenesis and depression: etiology or epiphenomenon? Biological Psychiatry 2004, 56:146-50.

11. Magariños AM, Deslandes A, McEwen BS: Effects of antidepressants and benzodiazepine treatments on the dendritic structure of CA3 pyramidal neurons after chronic stress. European Journal of Pharmacology 1999, 371:113-22.

12. Malberg JE, Eisch AJ, Nestler EJ, Duman RS: Chronic antidepressant treatment increases neurogenesis in adult rat hippocampus. Journal of Neuroscience 2000, 20:9104-10.

13. Vermetten E, Vythilingam M, Southwick SM, Charney DS, Bremner JD: Longterm treatment with paroxetine increases verbal declarative memory and hippocampal volume in posttraumatic stress disorder. Biological Psychiatry 2003, 54:693-702.

14. Ampuero E, Rubio FJ, Falcon R, Sandoval M, Diaz-Veliz G, Gonzalez RE, Earle N, Dagnino-Subiabre A, Aboitiz F, Orrego F, Wyneken U: Chronic fluoxetine treatment induces structural plasticity and selective changes in glutamate receptor subunits in the rat cerebral cortex. Neuroscience 2010, 169:98-108.

15. Guirado R, Varea E, Castillo-Gómez E, Gómez-Climent MA, Rovira-Esteban L, Blasco-lbáñez JM, Crespo C, Martínez-Guijarro FJ, Nàcher J: Effects of chronic fluoxetine treatment on the rat somatosensory cortex: activation and induction of neuronal structural plasticity. Neuroscience Letters 2009, 457:12-5.
16. Hajszan T, MacLusky NJ, Leranth C: Short-term treatment with the antidepressant fluoxetine triggers pyramidal dendritic spine synapse formation in rat hippocampus. European Journal of Neuroscience 2005, 21:1299-303.

17. Sairanen M, O'Leary OF, Knuuttila JE, Castrén E: Chronic antidepressant treatment selectively increases expression of plasticity-related proteins in the hippocampus and medial prefrontal cortex of the rat. Neuroscience 2007, 144:368-74.

18. Santarelli L, Saxe M, Gross C, Surget A, Battaglia F, Dulawa S, Weisstaub N, Lee J, Duman R, Arancio O, Belzung C, Hen R: Requirement of hippocampal neurogenesis for the behavioral effects of antidepressants. Science 2003, 301:805-9.

19. Sandi C: Stress, cognitive impairment and cell adhesion molecules. Nature Reviews Neuroscience 2004, 5:917-930.

20. Varea E, Blasco-lbáñez JM, Gómez-Climent MA, Castillo-Gómez E, Crespo C, Martínez-Guijarro FJ, Nácher J: Chronic fluoxetine treatment increases the expression of PSA-NCAM in the medial prefrontal cortex. Neuropsychopharmacology 2007, 32:803-12

21. Varea E, Castillo-Gómez E, Gómez-Climent MA, Blasco-Ibáñez JM, Crespo C, Martínez-Guijarro FJ, Nàcher J: Chronic antidepressant treatment induces contrasting patterns of synaptophysin and PSA-NCAM expression in different regions of the adult rat telencephalon. European Neuropsychopharmacology 2007, 17:546-57.

22. Rutishauser U: Polysialic acid in the plasticity of the developing and adult vertebrate nervous system. Nature Reviews. Neuroscience 2008, 9:26-35.

23. Varea E, Castillo-Gómez E, Gómez-Climent MA, Blasco-Ibáñez JM, Crespo C, Martínez-Guijarro FJ, Nàcher J: PSA-NCAM expression in the human prefrontal cortex. Journal of Chemical Neuroanatomy 2007, 33:202-9.

24. Varea E, Nácher J, Blasco-Ibáñez JM, Gómez-Climent MA, Castillo-Gómez E, Crespo C, Martínez-Guijarro FJ: PSA-NCAM expression in the rat medial prefrontal cortex. Neuroscience 2005, 136:435-43.

25. Nacher J, Lanuza E, McEwen BS: Distribution of PSA-NCAM expression in the amygdala of the adult rat. Neuroscience 2002, 113:479-84.

26. Seki T, Arai Y: Distribution and possible roles of the highly polysialylated neural cell adhesion molecule (NCAM-H) in the developing and adult central nervous system. Neuroscience Research 1993, 17:265-90.

27. Seki T, Arai Y: The persistent expression of a highly polysialylated NCAM in the dentate gyrus of the adult rat. Neuroscience Research 1991, 12:503-13.

28. Rousselot $\mathrm{P}$, Lois C, Alvarez-Buylla A: Embryonic (PSA) N-CAM reveals chains of migrating neuroblasts between the lateral ventricle and the olfactory bulb of adult mice. Journal of Comparative Neurology 1995, 351:51-61.

29. Nacher J, Blasco-lbáñez JM, McEwen BS: Non-granule PSA-NCAM immunoreactive neurons in the rat hippocampus. Brain Research 2002, 930:1-11.

30. Gómez-Climent MÁ, Guirado R, Castillo-Gómez E, Varea E, GutierrezMecinas M, Gilabert-Juan J, García-Mompó C, Vidueira S, SanchezMataredona D, Hernández S, Blasco-lbáñez JM, Crespo C, Rutishauser U, Schachner M, Nacher J: The Polysialylated Form of the Neural Cell Adhesion Molecule (PSA-NCAM) Is Expressed in a Subpopulation of Mature Cortical Interneurons Characterized by Reduced Structural Features and Connectivity. Cerebral Cortex 2010, 21:1028-41.

31. Nasrallah HA, Hopkins T, Pixley SK: Differential effects of antipsychotic and antidepressant drugs on neurogenic regions in rats. Brain Research 2010, 1354:23-9.

32. Couillard-Despres S, Wuertinger C, Kandasamy M, Caioni M, Stadler K, Aigner R, Bogdahn $U$, Aigner L: Ageing abolishes the effects of fluoxetine on neurogenesis. Molecular Psychiatry 2009, 14:856-64.

33. Marlatt MW, Lucassen PJ, van Praag H: Comparison of neurogenic effects of fluoxetine, duloxetine and running in mice. Brain Research 2010, 1341:93-9.

34. Navailles S, Hof PR, Schmauss C: Antidepressant drug-induced stimulation of mouse hippocampal neurogenesis is age-dependent and altered by early life stress. Journal of Comparative Neurology 2008, 509:372-81.

35. Kuhn HG, Dickinson-Anson H, Gage FH: Neurogenesis in the dentate gyrus of the adult rat ceases during aging. European Journal of Neuroscience 1995, 8(Suppl):89.

36. Varea E, Castillo-Gómez E, Gómez-Climent MA, Guirado R, Blasco-Ibáñez JM, Crespo C, Martínez-Guijarro FJ, Nácher J: Differential evolution of PSA- 
NCAM expression during aging of the rat telencephalon. Neurobiology of Aging 2009, 30:808-18.

37. Cowen DS, Takase LF, Fornal CA, Jacobs BL: Age-dependent decline in hippocampal neurogenesis is not altered by chronic treatment with fluoxetine. Brain Research 2008, 1228:14-9.

38. Magariños AM, McEwen BS: Stress-induced atrophy of apical dendrites of hippocampal CA3c neurons: involvement of glucocorticoid secretion and excitatory amino acid receptors. Neuroscience 1995, 69:89-98.

39. Marcuzzo S, Dall'oglio A, Ribeiro MFM, Achaval M, Rasia-Filho AA: Dendritic spines in the posterodorsal medial amygdala after restraint stress and ageing in rats. Neuroscience Letters 2007, 424:16-21.

40. Mitra R, Jadhav S, McEwen BS, Vyas A, Chattarji S: Stress duration modulates the spatiotemporal patterns of spine formation in the basolateral amygdala. Proceedings of the National Academy of Sciences of the United States of America 2005, 102:9371-6.

41. Radley JJ, Sisti HM, Hao J, Rocher AB, McCall T, Hof PR, McEwen BS, Morrison JH: Chronic behavioral stress induces apical dendritic reorganization in pyramidal neurons of the medial prefrontal cortex. Neuroscience 2004, 125:1-6.

42. Radley JJ, Rocher AB, Miller M, Janssen WGM, Liston C, Hof PR, McEwen BS, Morrison JH: Repeated stress induces dendritic spine loss in the rat medial prefrontal cortex. Cerebral Cortex 2006, 16:313-20.

43. Hansson AC, Nixon K, Rimondini R, Damadzic R, Sommer WH, Eskay R, Crews FT, Heilig M: Long-term suppression of forebrain neurogenesis and loss of neuronal progenitor cells following prolonged alcohol dependence in rats. International Journal of Neuropsychopharmacology 2010, 13:583-93.

44. McNamara RK, Able JA, Rider T, Tso P, Jandacek R: Effect of chronic fluoxetine treatment on male and female rat erythrocyte and prefrontal cortex fatty acid composition. Progress in Neuro-psychopharmacology \& Biological Psychiatry 2010, 34:1317-21.

45. Thompson MR, Li KM, Clemens KJ, Gurtman CG, Hunt GE, Cornish JL, McGregor IS: Chronic fluoxetine treatment partly attenuates the longterm anxiety and depressive symptoms induced by MDMA ('Ecstasy') in rats. Neuropsychopharmacology 2004, 29:694-704.

46. Hewlett WA, Trivedi BL, Zhang Z-J, de Paulis T, Schmidt DE, Lovinger DM, Ansari MS, Ebert MH: Characterization of (S)-Des-4-amino-3-[125I] iodozacopride ([125I]DAIZAC), a Selective High-Affinity Radioligand for 5-Hydroxytryptamine3 Receptors. Journal of Pharmacology and Experimental Therapies 1999, 288:221-231.

47. Li Q, Wichems CH, Ma L, Van de Kar LD, Garcia F, Murphy DL: Brain regionspecific alterations of $5-\mathrm{HT} 2 \mathrm{~A}$ and $5-\mathrm{HT} 2 \mathrm{C}$ receptors in serotonin transporter knockout mice. Journal of Neurochemistry 2003, 84:1256-1265.

48. McDonald AJ, Mascagni F: Neuronal localization of 5-HT type 2A receptor immunoreactivity in the rat basolateral amygdala. Neuroscience 2007, 146:306-20.

49. Morales M, Battenberg E, Bloom FE: Distribution of neurons expressing immunoreactivity for the $5 \mathrm{HT} 3$ receptor subtype in the rat brain and spinal cord. Journal of Comparative Neurology 1998, 402:385-401.

50. Puig MV, Santana N, Celada P, Mengod G, Artigas F: In vivo excitation of GABA interneurons in the medial prefrontal cortex through 5-HT3 receptors. Cerebral Cortex 2004, 14:1365-75.

51. Weber ET, Andrade R: Htr2a Gene and 5-HT(2A) Receptor Expression in the Cerebral Cortex Studied Using Genetically Modified Mice. Frontiers in Neuroscience 2010, 4.

52. Gilabert-Juan J, Castillo-Gomez E, Pérez-Rando M, Moltó MD, Nacher J: Chronic stress induces changes in the structure of interneurons and in the expression of molecules related to neuronal structural plasticity and inhibitory neurotransmission in the amygdala of adult mice. Experimental Neurology 2011, 232:33-40.

53. Castillo-Gómez E, Gómez-Climent MA, Varea E, Guirado R, Blasco-lbáñez JM, Crespo C, Martínez-Guijarro FJ, Nácher J: Dopamine acting through D2 receptors modulates the expression of PSA-NCAM, a molecule related to neuronal structural plasticity, in the medial prefrontal cortex of adult rats. Experimental neurology 2008, 214:97-111.

54. Tordera RM, Pei Q, Sharp T: Evidence for increased expression of the vesicular glutamate transporter, VGLUT1, by a course of antidepressant treatment. Journal of Neurochemistry 2005, 94:875-83.

55. Seki T, Arai Y: Different polysialic acid-neural cell adhesion molecule expression patterns in distinct types of mossy fiber boutons in the adult hippocampus. Journal of Comparative Neurology 1999, 410:115-25.
56. Kobayashi K, Ikeda Y, Sakai A, Yamasaki N, Haneda E, Miyakawa T, Suzuki H: Reversal of hippocampal neuronal maturation by serotonergic antidepressants. Proceedings of the National Academy of Sciences of the United States of America 2010, 107:8434-9.

57. Nacher J, Guirado R, Varea E, Alonso-Llosa G, Röckle I, Hildebrandt H: Divergent impact of the polysialyltransferases ST8Siall and ST8SialV on polysialic acid expression in immature neurons and interneurons of the adult cerebral cortex. Neuroscience 2010, 167:825-37.

58. Reinés $A$, Cereseto $M$, Ferrero A, Sifonios L, Podestá MF, Wikinski S: Maintenance treatment with fluoxetine is necessary to sustain normal levels of synaptic markers in an experimental model of depression: correlation with behavioral response. Neuropsychopharmacology 2008, 33:1896-908

59. Homberg JR, Olivier JDA, Blom T, Arentsen T, van Brunschot C, Schipper P, Korte-Bouws $G$, van Luijtelaar $G$, Reneman L: Fluoxetine exerts agedependent effects on behavior and amygdala neuroplasticity in the rat. PloS one 2011, 6:e16646.

60. Arivazhagan $P$, Panneerselvam C: Neurochemical changes related to ageing in the rat brain and the effect of DL-a-lipoic acid. Experimental Gerontology 2002, 37:1489-1494.

61. Blier P: Altered function of the serotonin $1 \mathrm{~A}$ autoreceptor and the antidepressant response. Neuron 2010, 65:1-2.

62. Hensler JG: Differential regulation of 5-HT1A receptor-G protein interactions in brain following chronic antidepressant administration. Neuropsychopharmacology 2002, 26:565-73.

63. Lolova I, Davidoff M: Changes in GABA-immunoreactivity and GABAtransaminase activity in rat amygdaloid complex in aging. Journal für Hirnforschung 1991, 32:231-8.

64. Nakanishi H: Hyperexcitability of amygdala neurons of SenescenceAccelerated Mouse revealed by electrical and optical recordings in an in vitro slice preparation. Brain Research 1998, 812:142-149.

65. Marcusson J, Morgan D, Winblad B, Finch C: Serotonin-2 binding sites in human frontal cortex and hippocampus. Selective loss of S-2A sites with age. Brain Research 1984, 311:51-56.

66. Mcewen BS, Magarinos AM, Reagan LP: Structural plasticity and tianeptine: cellular and molecular targets. Psychiatry: Interpersonal and Biological Processes 2002, 5-9.

67. Slotkin TA, McCook EC, Ritchie JC, Carroll BJ, Seidler FJ: Serotonin transporter expression in rat brain regions and blood platelets: aging and glucocorticoid effects. Biological Psychiatry 1997, 41:172-83.

68. Huang G-J, Herbert J: Stimulation of neurogenesis in the hippocampus of the adult rat by fluoxetine requires rhythmic change in corticosterone. Biological Psychiatry 2006, 59:619-24.

69. Seib LM, Wellman CL: Daily injections alter spine density in rat medial prefrontal cortex. Neuroscience Letters 2003, 337:29-32.

70. Nacher J, McEwen BS: The role of N-methyl-D-asparate receptors in neurogenesis. Hippocampus 2006, 16:267-70.

71. Markwardt S, Overstreet-Wadiche L: GABAergic signalling to adultgenerated neurons. Journal of Physiology 2008, 586:3745-9.

72. Marlatt MW, Philippens I, Manders E, Czeh B, Joels M, Krugers H, Lucassen PJ: Distinct structural plasticity in the hippocampus and amygdala of the middle-aged common marmoset (Callithrix jacchus). Experimental neurology 2011, 230:291-301.

73. Castrén E, Rantamäki T: The role of BDNF and its receptors in depression and antidepressant drug action: Reactivation of developmental plasticity. Developmental Neurobiology 2010, 70:289-97.

74. Wu X, Castrén E: Co-treatment with diazepam prevents the effects of fluoxetine on the proliferation and survival of hippocampal dentate granule cells. Biological Psychiatry 2009, 66:5-8.

75. Li Y-F, Zhang Y-Z, Liu Y-Q, Wang H-L, Cao J-B, Guan T-T, Luo Z-P: Inhibition of $\mathrm{N}$-methyl-D-aspartate receptor function appears to be one of the common actions for antidepressants. Journal of Psychopharmacology 2006, 20:629-35.

76. Saarelainen $T$, Hendolin P, Lucas $G$, Koponen E, Sairanen M, MacDonald E, Agerman K, Haapasalo A, Nawa H, Aloyz R, Ernfors P, Castren E: Activation of the TrkB Neurotrophin Receptor Is Induced by Antidepressant Drugs and Is Required for Antidepressant-Induced Behavioral Effects. Journal of Neuroscience 2003, 23:349-357.

77. Banasr M, Hery M, Printemps R, Daszuta A: Serotonin-induced increases in adult cell proliferation and neurogenesis are mediated through different 
and common $5-\mathrm{HT}$ receptor subtypes in the dentate gyrus and the subventricular zone. Neuropsychopharmacology 2004, 29:450-60.

78. Ohira K, Miyakawa T: Chronic treatment with fluoxetine for more than 6 weeks decreases neurogenesis in the subventricular zone of adult mice. Molecular Brain 2011, 4:10.

79. Sairanen $M$, Lucas $G$, Ernfors P, Castrén M, Castrén E: Brain-derived neurotrophic factor and antidepressant drugs have different but coordinated effects on neuronal turnover, proliferation, and survival in the adult dentate gyrus. Journal of Neuroscience 2005, 25:1089-94.

80. Roozendaal B, MCEwen BS, Chattarji S: Stress, memory and the amygdala. Nature Reviews Neuroscience 2009, 10:423-33.

doi:10.1186/1471-2202-13-5

Cite this article as: Guirado et al.: Chronic fluoxetine treatment in

middle-aged rats induces changes in the expression of plasticity-related molecules and in neurogenesis. BMC Neuroscience 2012 13:5.

\section{Submit your next manuscript to BioMed Central} and take full advantage of:

- Convenient online submission

- Thorough peer review

- No space constraints or color figure charges

- Immediate publication on acceptance

- Inclusion in PubMed, CAS, Scopus and Google Scholar

- Research which is freely available for redistribution

Submit your manuscript at www.biomedcentral.com/submit 